\title{
Lights, Camera, Action: Instructor-Made Videos (IMVs) Transforming Diagnostic Audiology Teaching
}

\author{
Keran L. Jervis ${ }^{1}$, Dieter J. Schönwetter ${ }^{2}$ \& Giriraj S. Shekhawat ${ }^{1,3,4}$ \\ ${ }^{1}$ Ear Institute, University College London, London, England \\ ${ }^{2}$ Rady Faculty of Health Sciences, Dr. Gerald Niznick College of Dentistry, University of Manitoba, Winnipeg, \\ Manitoba, Canada \\ ${ }^{3}$ College of Nursing and Health Sciences, Flinders University, Adelaide, Australia \\ ${ }^{4}$ Tinnitus Research Initiative, Germany \\ Correspondence: Giriraj S. Shekhawat, Flinders Medical Centre, GPO Box 2100, Adelaide 5001, South Australia.
}

Received: February 17, 2020

Accepted: April 8, 2021

Online Published: April 12, 2021

doi:10.5430/ijhe.v10n5p46

URL: https://doi.org/10.5430/ijhe.v10n5p46

\begin{abstract}
This study investigated the effects of the application of instructor-made videos (IMVs) on a population of first-year master's in audiology students. The investigation sampled 10 students and investigated both their perception of IMVs as a tool and the empirical effects of the tool. This study examined how IMVs can be applied specifically in conjunction with traditional lecturing techniques. The methodology included surveys and interviews before and after exams. The findings demonstrated that the effect of IMVs is largely positive, particularly as indicated by students and, to a lesser degree, by the increase in grades. Wider research from external sources is consistent with this conclusion. Suggestions for further research, including expansion to subjects outside the field of audiology and an investigation into continued and refreshed post-education learning are made.
\end{abstract}

Keywords: instructor-made videos, audiology, Edmund's learning styles, higher education, qualitative, quantitative, perception, technology-enhanced learning

\section{Introduction}

The lecture continues to be the most popular method of teaching students in the health sciences. COVID-19 challenged the lecture method, with concerns arising at all levels of education. According to Crawford et al. (2020), 'Migrating from traditional or blended learning to a fully virtual and online delivery strategy [can]not happen overnight and [was initially] associated with many challenges [and] many questions' (p. 11). Ironically, as the more popular teaching method, lectures create the lowest information retention rates for examinations and for the transfer of learning from classrooms to clinics (Subramanian et al., 2012). As a result of this disparity, various teaching resources have been created to complement or compensate for the lecture method, including synchronous and asynchronous online learning (King et al., 2010), game-based learning (Gee, 2007), simulations (Corbridge et al., 2010), and videos (Tymczyńska, 2009). Instructor-made videos (IMVs) are concise 3-to-10-minute information-dense videos conveying visual information in a way that differs from learning styles (LS) that are more traditional (Pan et al., 2012). IMVs scaffold student learning and complement the primary learning source. As a multimodal method of learning (e.g. a combination of demonstration, presentation and illustration), IMVs positively affect student learning. This study investigated the use and impact of IMVs on the learning of information and on adaptation to new techniques within the field of audiology.

IMVs have their roots in 'instructor-developed materials' (Kessler \& Plakans, 2001). Early forms of IMVs were rudimentary, intended as a supportive tool to educate multiple students concurrently. More recently, IMVs have been used to personalise learning and boost student achievement. IMVs are particularly effective scaffolding tools to transform abstract concepts into concrete reality for students (McAlister, 2014). IMVs cover a specific topic or concept to scaffold learning and enhance understanding. IMVs allow students to witness practical applications of subject matter they have learnt in a safe, casual, and non-judgemental environment. Many concepts are far easier to grasp once the student has witnessed them (e.g. masking in audiology), so IMVs are particularly useful for conceptually difficult topics (Pan et al., 2012). Moreover, IMVs allow students to brush up on skills within a matter of minutes at any time and at any place; they are a form of just-in-time learning (Ranga, 2017). From their inception, IMVs have been ubiquitous among various strands of the educational sphere such as play skills for early age students (Palechka \& MacDonald, 2010), 
cooking skills for high school students (Mechling et al., 2013), and educational and pastoral skills in graduate school students (Shackelford \& Maxwell, 2012). Hence, IMVs empower students to learn, granting them more time to focus on challenging concepts in more engaging ways.

Despite their increasing popularity (Pan et al., 2012), research on IMVs is limited. A detailed literature search involving ResearchGate, Google Scholar, and PubMed databases was implemented with the combination of the following keywords: 'instructor-made video/s', 'IMV/s', 'quantitative', 'qualitative', and 'education'. A total of six primary research studies were found that met the search criteria. The research methodologies for these studies included questioning and analysis through perception-based Likert scales (Rose, 2009; Pan et al., 2012) as well as more objective comparisons of test scores (Aragon \& Wickramasinghe, 2016; Hajhashemi et al., 2017; Ranga, 2017). Some recorded quite low response rates compared with the number of students in class (Pan et al., 2012; Ranga, 2017; Rose, 2009). Most relied on open-ended questions (Hajhashemi et al., 2017; Pan et al., 2012; Ranga, 2017; Rose, 2009). Others utilised longitudinal methods (Pan et al., 2012; Ranga, 2017), whereas some used only short-term measures of learning and knowledge (Hajhashemi et al., 2017). Study sample sizes ranged from 11 to 48 participants. One study included a large sample size and tracked 29 videos over time.

Rose (2009) provided critical context in the early years of research into IMVs, citing 3.2 million U.S. students in higher education who participated in online courses. Pan et al. (2012) focused purely on streamed videos targeting problematic topics in the sciences. These videos sought to bridge the gap between abstract theories and concrete realities more efficiently, easily, and enjoyably. Hajhashemi et al. (2017) explored the power of short videos using animation and simulations and found these helped students retain focus, increase attention, and enhance motivation. Hence, intriguing learners through creative animations and simulations increased student learning. Schönwetter et al. (2016) found longer retention rates for students who were provided videotaped lectures; however, extraneous variables such as not being able to control the playback of the teaching videos challenged short-term learning outcomes. Aragon and Wickramasinghe (2016) found that enhancing student learning was less dependent on how long each student had with the content material and more dependent on the student's ability to understand the concepts in every video, supporting the idea that personalised learning is vital. Thus, the most influential factor for scaffolding learning through IMVs is the ability to personalise the learning with universal factors. For example, the palpability of problematic and abstract concepts and the personalised ability to pause, rewind, and re-watch sections of videos influence successful learning more than a video does.

Although these initial studies provide early exploratory findings on the impact of IMVs, there are some unanswered questions. First, what is the impact of IMVs in terms of enhancing students' visualisation and the palpability of methods covered? Second, to what extent is the learning transfer enhanced from the IMV to patient care? Third, how do IMVs assist real-world learning of theories and practical applications? Fourth, how can IMVs remain efficient and not compromise education? Finally, how are practise errors in the initial application of IMVs minimised?

Given the current limitations of IMV research, this study addresses some of these gaps by exploring how IMVs impact student learning. Because IMVs are particularly useful for translating theoretical concepts into reality, diagnostic audiology was chosen as the content discipline. The foci of the current study include the following:

- assessing the impact of IMVs to aid in the visualisation and palpability of methods and procedures carried out on patients,

- $\quad$ observing how these real-world applications through IMVs make theoretical and practical connections 'click' for students,

- exploring the efficiencies of this method of learning for teachers and students without compromising quality, and

- minimising errors prevalent during the initial practice of these techniques because IMVs solidify abstract concepts into concrete ideas for students.

\section{Methods}

Because of the nature of the study, this work was exempt from ethical approval in accordance with the guidelines provided by XXXX. The Internal Ear Institute Review Committee ruled on this.

\subsection{Participants}

The initial goal was to interview twenty participants. However, because of the COVID-19 lockdown, time commitments and availability of volunteers reduced the sample to 10. Given that the research focused on the application of IMVs in the field of audiology, participants had to complete the Diagnostic Audiology module in XX's Ear Institute during the 
2019-2020 academic year. The choice of this module was twofold: first, because it is a core module within audiology, more students complete it, providing a potentially larger sample to draw from; and second, this module requires students to translate theoretical knowledge into practical skills. This study is divided into four stages, as illustrated in Figure 1.

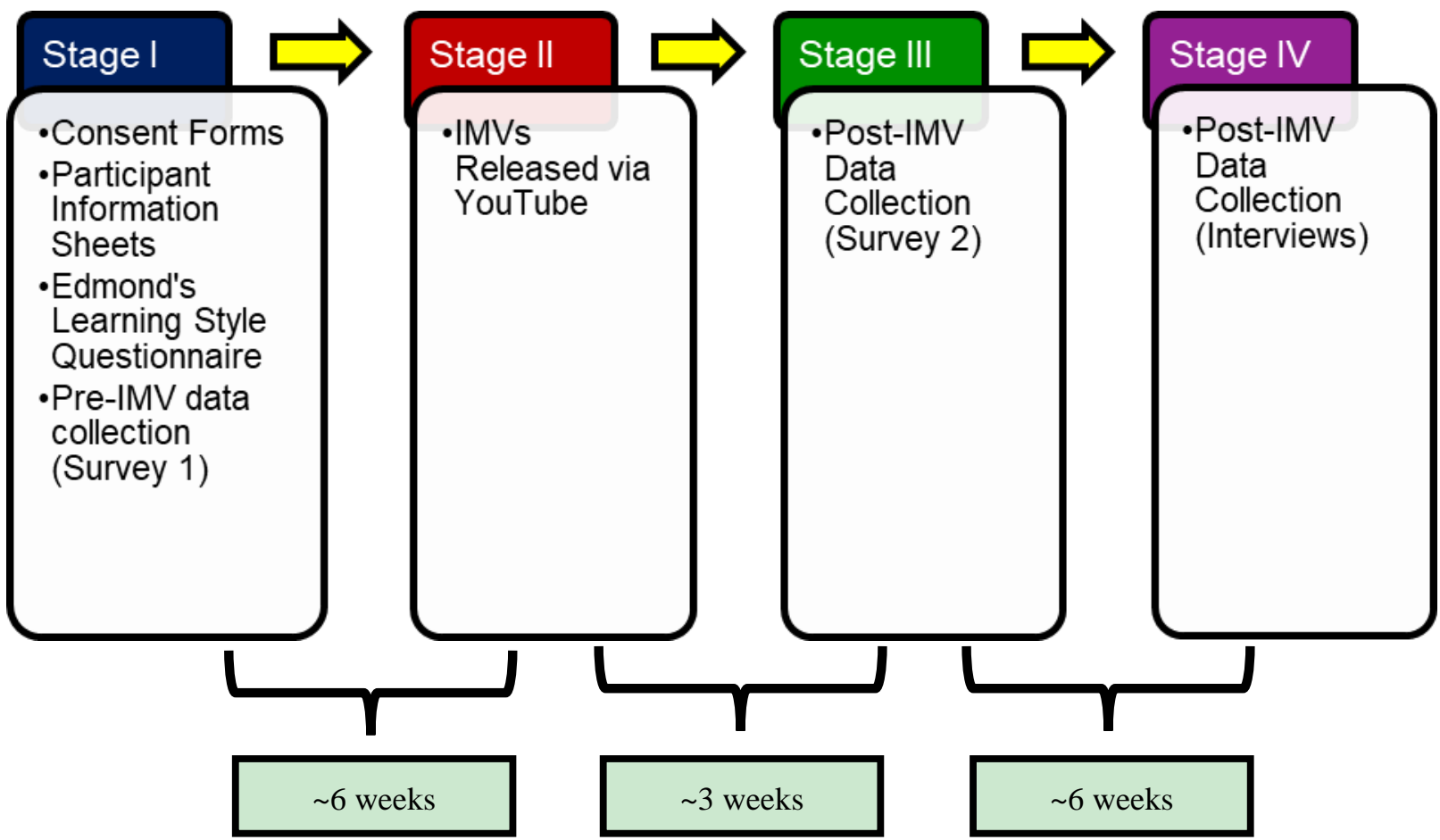

Figure 1. Stage Guide

\subsection{Stage I}

As seen in Figure 1, in the first stage, participants were given study information and consent forms to explain what they needed to know for the study and to ensure they understood their rights and consented to the use and analysis of their data. Following signed consent, each participant randomly selected a set of papers containing two-thirds of a coded identity. Each randomly coded identity had a colour and animal combination (e.g. coral cow) that made up two-thirds of the coded identity. The final piece, which the participant decided, was either their favourite city or best friend's name. These steps ensured complete anonymity. Each participant's randomly coded identity remained unknown to the researchers throughout the experiment.

Edmond's Learning Style Questionnaire (Reinert, 1976) ascertained which LS (i.e. listening, activity, visual, or written word), best described each participant. These data allow contextual information to be applied to each participant's views regarding their comfort with and perception of IMVs that primarily focus on visual and listening LSs. Participants were also required to complete a pre-IMV exposure survey, providing part of the hard data results in this study. Quantitative and qualitative data were combined throughout this study to provide a holistic view (Sandelowski, 2000) of student learning in addition to a comparison of 'exam-style' question scores because, ultimately, students learn more when they enjoy the learning process (Blunsdon et al., 2003).

\subsection{Stage II}

As Figure 1 shows, approximately six weeks following initial data collection, the five IMVs were released to the participants. The content of the five IMVs was altered slightly to become more 'top-tip' orientated, involving creative methods of revision (i.e. they now needed to be created in isolation during lockdown) rather than a physical walk-through involving clinical equipment. Fortunately, the topic areas remained the same and involved topics that were determined to be essential and/or difficult by the 2019/2020 cohort through an informal class discussion. These topics were translated into videos (see Appendix A for more details).

All IMVs involved animations, appropriately added and edited audio, annotations, and titles and handwritten prompts when required to aid in the visualisation of concepts, particularly those involving numbers. The combination of activities within the IMVs aimed to cover aspects from each LS. To ensure user-friendly access to IMVs, they were uploaded to YouTube with privacy settings as 'unlisted'; only participants could access them. The primary researcher 
solely created and edited the IMVs (Hardware: iPhone 7; 2018 13-inch MacBook Pro; Software: iMovie and Logic Pro $\mathrm{X})$.

\subsection{Stage III}

Figure 1 describes the third stage. Participants had full access to the IMVs for approximately three weeks until the post-IMV survey was distributed via email using Microsoft Forms; the survey remained open for one week. Participants also received two reminders about this survey, one day before closing and one hour before closing. Each participant used their randomly coded identity to complete the survey, which contained a range of information similar to the pre-IMV survey. These surveys were distributed when summer final exams were imminent and included this information, meaning that participants needed to apply and translate their knowledge into both theoretical and practical settings (because the Diagnostic Audiology exams involve written and physical components). This is notable because the next stage involved a comparison between the perception of accomplishment and confidence in knowledge over time.

\subsection{Stage IV}

As Figure 1 shows, just under six weeks after the survey mentioned in Stage III was closed (and following the Diagnostic Audiology exams), each participant was interviewed over Zoom to obtain information regarding the influence of IMVs during the exam season and to enquire whether any of their opinions had changed over a longer period. Because the method of data collection for this included an interview, it mainly involved acquiring quantitative data through closed-ended questions, with one follow-up open-ended question.

Each participant was asked to compare certain aspects of learning and revision between traditional lectures and IMVs, to state their preferred learning or revision method (e.g. closed-ended questions), to provide an explanation involving their thinking and decision-making process for each answer, and to provide any other information regarding their experience (Green et al., 2012). If participants had queries regarding the questions because of language or translation barriers, the questions were rephrased and elaborated on prior to the answer being transcribed. This allowed for clarification of study-specific questions as well as additional information that may have assisted with contextual information regarding the results (Creswell et al., 2003).

A second interview was conducted approximately 16 weeks from the start of the study. This long-term follow-up interview captured participants' changed opinions regarding scaffolding learning through the use of IMVs and captured why the change occurred. The extended interval also allowed questions regarding the application of knowledge (summer exam season). This is notable because such situations can influence personal awareness and perceptions of certain aspects within the learning and revision process (such as efficiency and accomplishment) and perhaps cause perceptions to change (Alpay \& Walsh, 2008).

\section{Results}

In this section, each of the surveys and interviews will be comprehensively broken down to provide an outline of the results the 10 participants produced in this study.

The analysis of the Edmond's Learning Style Questionnaire showed that although they were only tested on a small sample, every LS was identified (Visual $=5$, Activity $=4$, Listening $=2$, Written Word $=2$ ). This highlights the variety of LSs within classes, supporting the idea that a standardised method of teaching and learning is not appropriate. Moreover, in looking at the top two LSs for each participant, the LS for this cohort of participants changes slightly (Visual \& Activity $=2$, Visual and Listening $=1$, Visual $=2$, Activity $=2$, Listening $=2$, Written Word $=1$ ). A notable highlight of this information is the prevalence of activity learners within the Diagnostic Audiology cohort.

\subsection{Survey 1}

The knowledge test section of the survey captured a mean knowledge test score of $77 \%$ to 1 d.p. (76.6\% with a standard deviation of $\pm 8.609[ \pm 11.24 \%])$.

The quantitative data indicated that the pace of traditional lecturing methods for participants elicited no strong response on either side of the modal response, being 'okay'. Responses ranged from 'very bad' (20\%), 'bad' (20\%), and 'okay' $(30 \%)$ to 'good' $(30 \%)$ and 'very good' $(0 \%)$. A similar modal response of 'neutral' permeated the perceived comfort level the participants experienced within traditional lectures. Responses scaled from 'very uncomfortable' $(0 \%)$, 'uncomfortable' $(10 \%)$, and 'neutral' $(60 \%)$ to 'comfortable' $(30 \%)$ and 'very comfortable' $(0 \%)$.

In particular, the perceived confidence within knowledge results did not coincide as one might expect. The results regarding confidence within each specific subject area ranged across the whole scale from 'very uncertain', 'uncertain', and 'neutral' to 'confident' and 'very confident', with the modal varying between each subject area from 'uncertain' 
( $50 \%$ for masking theory), 'neutral' ( $40 \%)$, 'confident' ( $40 \%$ for pure-tone audiometry [PTA]), and 'confident' ( $40 \%$ for the rules of masking) to 'very confident' ( $60 \%$ for the types of hearing loss). In contrast, when compared to the confidence scores, the highest-scoring topic in the knowledge-based section, with $100 \%$ accuracy across all participants, was masking theory; and the lowest topic, with $30 \%$ accuracy, was PTA.

This survey provided additional insights into aspects of traditional lecture-style learning that participants did or did not enjoy. Participants clearly enjoyed two main aspects of lectures: the ability to ask questions and seek immediate clarification (30\%) and the idea of communal learning where everyone works on (and learns) the same material (20\%). Furthermore, participants highlighted four clear characteristics of lecture-style content delivery they did not enjoy: the lack of breaks (30\%), 'boring' delivery (30\%), inability to maintain the pace the lecturer set $(30 \%)$, and distractions within the environment (e.g. latecomers, 40\%). These were a prolific set of factors throughout the interviews. Even though this is qualitative information, it provides meaningful insights into the perceptions of the participants.

\subsubsection{Post-IMV Data}

Participant engagement with the IMVs was followed by a survey and an interview.

\subsection{Survey 2}

The post-exam Survey 2 provided direct and comparable differences between knowledge test scores pre- and postexposure as well as insights into participants' perceptions of their learning experiences. As Figure 2 shows, Survey 2 showed an increase from the Survey 1 score of $77 \%$ to $80 \%$ to 1 d.p. (79.8\% with a standard deviation of \pm 8.086 $[ \pm 10.13 \%])$.

Based on $\mathrm{Chi}^{2}$ tests, differences were explored among Test Performance X Learning Style, Recommendation of IMVs $\mathrm{X}$ Post-IMV Test Score, and Pre-IMV Test Score X Post-IMV Test Score. In each case, no statistically significant findings were found, $X 2(1, N=8)=4.58, p=.80 ; X 2(1, N=18)=18.57, p=.83 ; X 2(1, N=9)=13.24, p=.37$, respectively. Outcomes were affected.

\subsubsection{Survey Open-ended Questions}

Participants were asked how the animation and visual factors aided their consolidation of the knowledge transferred through the IMVs. It was determined that the ability to remember the knowledge within 'PTA Top Tips' was universally improved, and the same applies to the ' 3 Rules of Masking'. When asked about the ' 3 Rules of Masking Song', 70\% of participants said it aided their consolidation. However, $30 \%$ of participants disagreed, saying it did not.

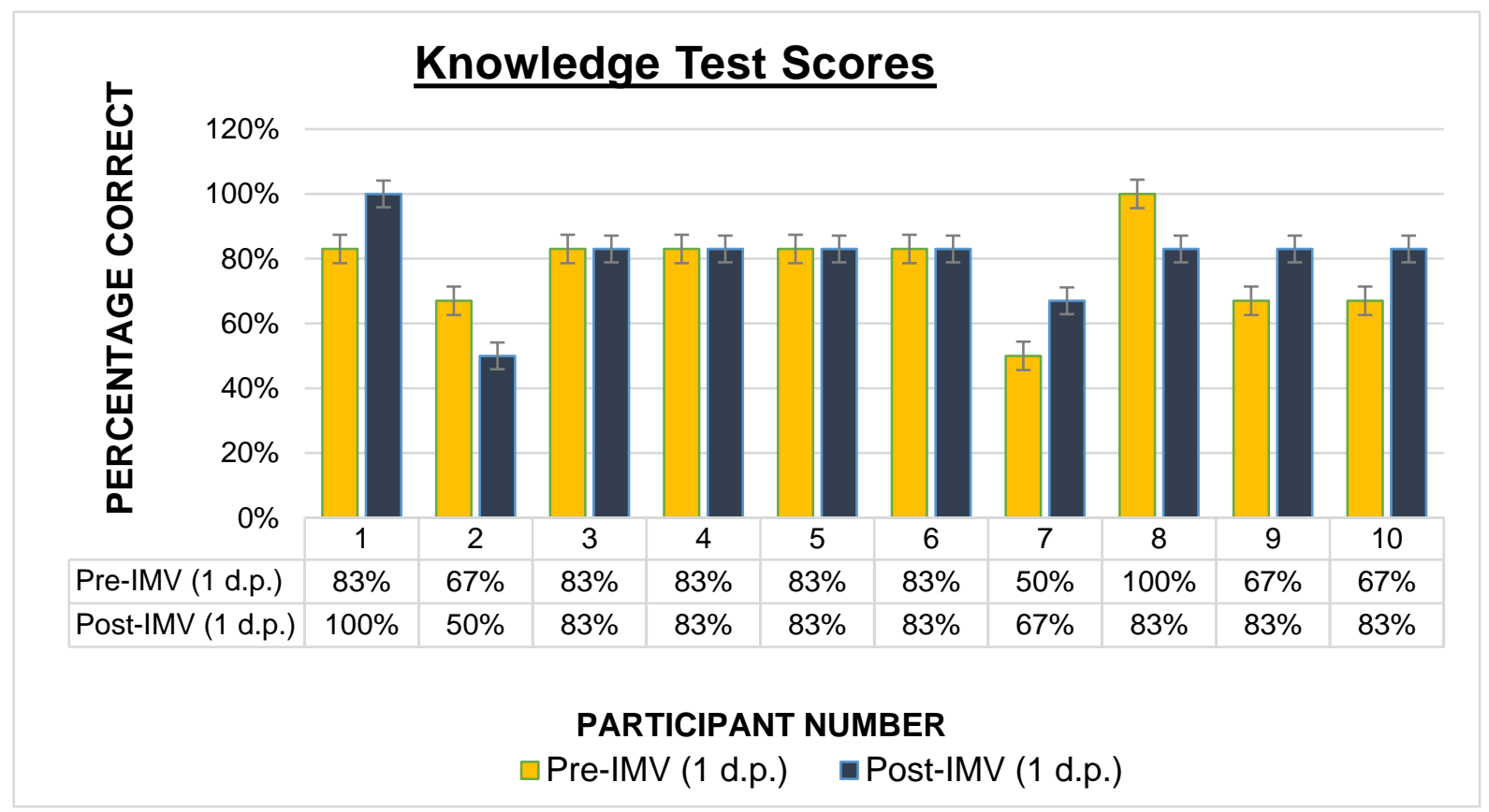

Figure 2. Raw Data [3], 2020: Knowledge-based Test Scores Pre- and Post-IMV Exposure for Each Participant with Standard Error Bars 
Notably, $20 \%$ of the $30 \%$ for whom the song did not provide consolidation, was because of a language barrier and unfamiliarity with the song, which detracted from the information participants were trying to remember. In 'Degrees of Hearing Loss', $80 \%$ of participants gave positive feedback, and the remaining $20 \%$ felt that the concepts were simple enough that no memory aid was required. Finally, the same $80 \% / 20 \%$ participant split was observed with 'Types of Hearing Loss', where the same $20 \%$ expressed identical opinions, stating that no aid was required for this subject area. As seen in Figure 3, most participants were highly likely to or definitely would recommend some of the videos to others. One participant said they would not recommend the IMV with the song because of the language barrier.

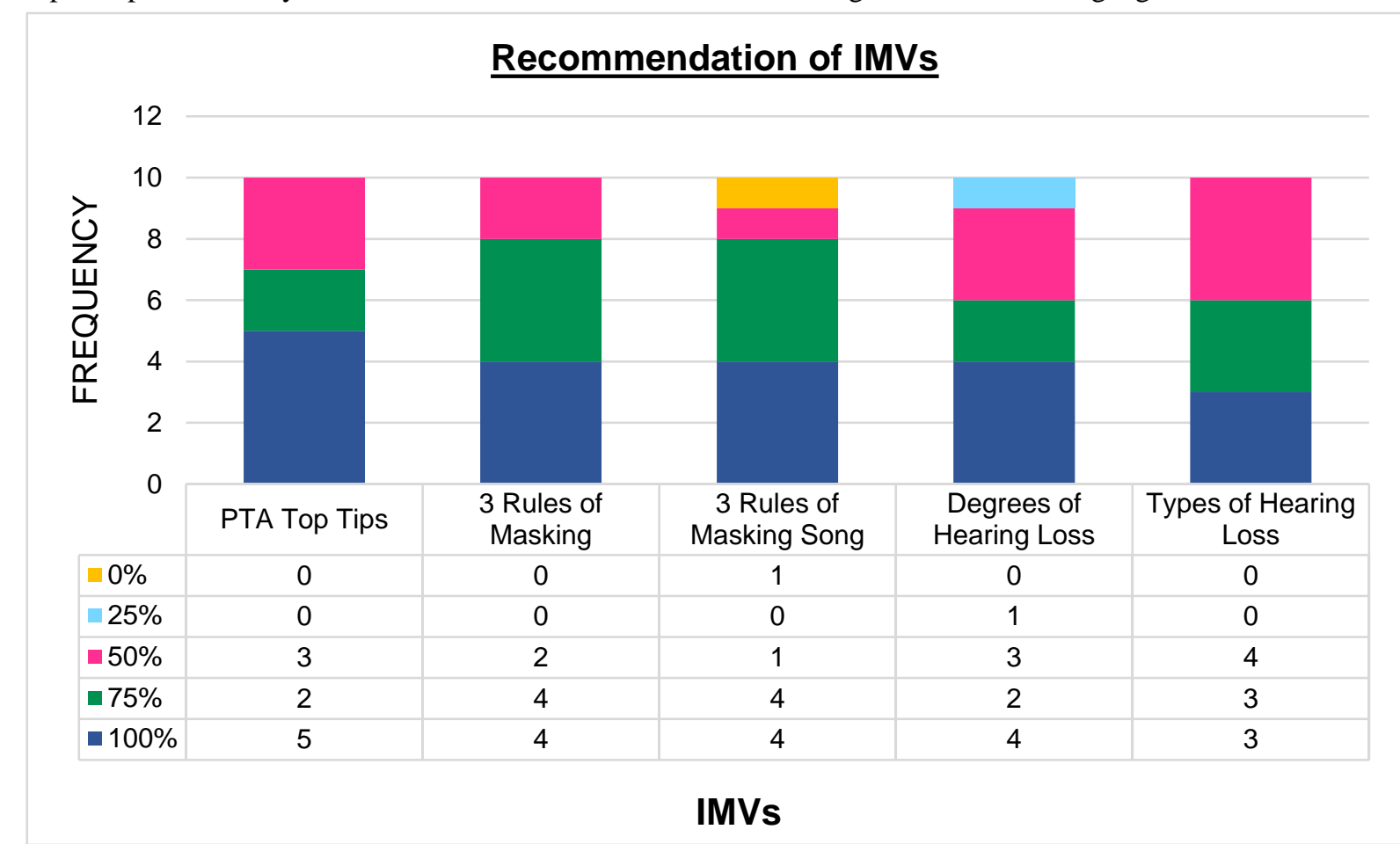

Figure 3. Raw Data [5], 2020: Bar Graph Showing the Percentage of Recommendations of Each of the IMVs Note. Likert scale options included $0 \%, 25 \%, 50 \%, 75 \%$, and $100 \%$.

\subsubsection{Postsurvey}

The postsurvey asked about the continued use of IMVs as an additional learning tool, scaled from 'not at all', 'not significantly', 'neutral', and 'a little bit' to 'absolutely'. Most participants (80\%) gave a positive review, stating the videos were replayable and a great supplement. Of this group, $75 \%$ said they would 'absolutely' continue their use, and $25 \%$ said they would continue it 'a little bit'. Of the overall group, $10 \%$ responded neutrally to the continued use of IMVs, and the remaining $10 \%$ reviewed them negatively, saying they would not use them a great deal.

\subsection{Interview 1}

The Zoom interviews focused on comparing the scaffolding through lectures and IMVs and were conducted following the second survey and after all exams had taken place. Overwhelming responses indicated a strong preference for IMVs over traditional methods of teaching.

Table 1. Raw Data [4], 2020: Summarised Comparison of IMVs and Traditional Lectures in Particular Aspects

\begin{tabular}{cccc}
\hline & IMV & Lecture & Both/Neutral \\
\hline Comfortable? & $40 \%$ & $0 \%$ & $60 \%$ \\
Confident? & $80 \%$ & $10 \%$ & $10 \%$ \\
In control? & $90 \%$ & $10 \%$ & $0 \%$ \\
Accomplished? & $80 \%$ & $10 \%$ & $10 \%$
\end{tabular}

Data indicated a remarkable increase in confidence in material produced through IMVs ( $80 \%$ preferring IMVs and the remaining $20 \%$ split evenly between lectures and remaining neutral). Regarding the feeling of being in control of their 
learning, $90 \%$ of participants felt more control using IMVs, with only $10 \%$ preferring lectures. Ultimately, $80 \%$ felt more accomplished with their learning after using IMVs to scaffold their learning (the other 20\% again split between lectures and remaining neutral). When asked in more detail about IMVs compared with traditional lectures, interviewees expanded on several specific areas.

Participants indicated they enjoyed the increased level of control, and the majority (70\%) stated they enjoyed the ability to control and guide their own experience. Being able to pause and rewind videos to replay points they needed to personally review was the main reason cited. Using IMVs is clearly easier than asking a lecturer to go over a point repeatedly, which could also affect others' learning experience. Of the remaining $30 \%$ of participants who did not enjoy the control they had with the IMVs, $10 \%$ stated this was because of a personal lack of familiarity with the software. A further $10 \%$ had no feelings regarding the control of the IMVs, whereas the remaining $10 \%$ liked the structure of lectures and control of the IMV equally. The final $10 \%$ who expressed an equal liking for IMVs and traditional lectures specifically stated that the routine structure traditional lectures imposed was beneficial for them, but the IMV was beneficial because it helped consolidate knowledge.

Every participant (100\%) said they would recommend IMVs to others. Most participants (70\%) stated that the IMVs had a positive impact on their exam revision, and $90 \%$ said they helped in the transfer from theoretical knowledge to practical application, specifically concerning practical exams. It is important to note a consensus regarding the remaining $30 \%$ of participants, who stated IMVs did not affect their revision, because they felt they did not need to revise these specific subject areas, because of their personal preferences regarding the content of the module (they would find IMVs more useful for other modules' contents, such as 'Anatomy and Physiology of the Audio-Vestibular System'), or a change in the nature of exams this academic year because of COVID-19. They believed revision to be 'almost obsolete' because exams were 24 hours long, open book, and online but nevertheless believed that IMVs would have been more useful and impactful if traditional exams had taken place.

\section{Discussion}

The primary objective of this study was to identify whether IMVs were beneficial and whether they could be used to augment learning in audiology. There were three categories of findings. First, the predominant LS was visual, whether exclusive or in combination with another LS. The success of IMVs in both perceived and actual achievement may be a result of the synergy among the LSs. IMVs unquestionably permeate visual and listening styles compared with the primary LS of written words and listening used in lecture delivery. Hence, students struggling with learning concepts outside of their predominant LS may benefit from IMVs.

Audiology is a clinical career within a practical healthcare domain, highlighting the need for personalised and combination learning when training future audiology professionals. Hence, IMVs that include a combination of visual and activity LSs have a compensatory impact on students exposed to traditional lectures, which perpetuates auditory and written LS. Notably, the results of Survey 1 indicated that the highest scoring participant (100\%) exhibited the only combination of visual and listening LSs, which may partially explain why traditional lecture style syllabus delivery worked so well for them.

Second, IMVs were perceived as supportive educational tools and boosted students' academic performance. The ubiquity of lecturing is arguably not matched by the enthusiasm of those subjected to it daily, and to this end, an improvement in the enjoyment of a learning method can increase students' engagement. Overall, participants enjoyed IMVs, would continue to use them as supplementary tools, and would recommend them to others as a tool to scaffold learning. Ranga (2017) also found overwhelming support by students for the positive impact of IMVs. Pan et al.'s (2012) investigation paralleled the current study. Their sample perceived IMVs as having a positive impact on their learning; in that study, 30 of 32 students viewed them as 'very favourable' or 'favourable'. Moreover, Pan et al. reported that having control over the pace of learning using video controls for students (i.e. pause, play, rewind, fast forward, etc.) was an important factor defining IMVs as effective, especially in the context of online courses.

Third, the use of IMVs increases participants' ability to answer knowledge-based questions. This is notable because during informal discussions with students before designing the IMVs, masking as compared to PTA content was defined as more complex. Notably, Aragon and Wickramasinghe (2016) showed that the grades of students who implemented IMVs improved. Pan et al. (2012) found that IMVs promote success when used in conjunction with lectures. Combining LSs is the most effective way of teaching a larger group of students (Hajhashemi et al., 2017; Murphy et al., 2004; Pan et al. 2012) and is especially effective when combining IMVs with lectures. This concept is consistent with other research demonstrating students' preference for learning in a multisensory environment (Hajhashemi et al., 2017). Referencing results from this investigation, if only $40 \%$ of participants' needs are met with standardised teaching and this can be increased to $80 \%$ with a combination of methods, it seems logical to combine the two methods. Even though most 
participants had generally positive experiences with IMVs, some students did not enjoy certain aspects of them. Most of these responses might be explained by conflicting perceived LSs.

This study adds to the scientific literature in various ways. It showed that most participants used IMVs of their own volition, going beyond the scope of this research study. This clarifies why they were recommended: it is always better to have access to the tool and not use it than to not have access at all. This concept largely remained the same from pre- to post-exam data (increasing the recommendation rate from $90 \%$ to $100 \%$ ). Participants who increased their positive perceptions of IMVs noted that their enjoyment of the IMVs directly correlated with the quality of the IMVs that were produced and their previous negative perceptions were the result of only having been exposed to IMVs they deemed 'boring'. Thus, appealing IMVs increase student engagement, which in turn affects their perceptions of IMVs' value.

Significantly, the study findings present both perceived and hard measures of the effects of IMVs on the sample of audiology students. This is incredibly useful because this group is mostly untapped in research; expanding the field of educational research among a diverse pool of populations can only bring greater benefits. The use of the pre- and post-surveys coupled with learning styles yielded a broader understanding of participants' perceptions. Likert scales were used to standardise the views of participants, allowing comparison to other studies. Moreover, surveys were taken before and after summer exams, inviting more objective and direct questioning about students' personal application of IMVs as a revision tool (by choice) at a key time in students' academic careers.

Several factors could have affected the study results. Because of COVID-19, the sample size was reduced. Future research would require larger sample sizes to improve data integrity. Moreover, the sample was restricted to a class of audiology master's degree students. Although this is a limitation, it was important to demonstrate the transference of learning from IMVs to patient care. Further research could compare science- and arts-based courses to determine whether IMVs are more influential in some disciplines than others. Time constraints due to COVID-19 reduced the investigation of the long-term impact of IMVs. Future research should focus on both the short- and long-term influence of IMVs on student performance and perception. Future research might identify a control group of students who have not been previously exposed to IMV-like tools and compare them to students who have had such exposure to rule out maturation effects. Finally, future research needs to extrapolate whether the introduction of IMVs as a learning tool is inherently beneficial or simply a new and exciting stimulus to improve learning.

\section{Conclusions}

There are significant statements that have been shown to be true. First, students perceive IMVs as a useful scaffolding tool. Second, students would recommend them to other learners. Third, IMVs are useful in helping students improve their knowledge-based test scores. These findings support and extend previous research explorations into IMVs and provide important directions for future research on IMVs. Last, this study added value to the healthcare discipline of audiology.

\section{Acknowledgements}

A sincere thank you to all who supported, critiqued, and proofread this article. You know who you are.

\section{References}

Alpay, E., \& Walsh, E. (2008). A skills perception inventory for evaluating postgraduate transferable skills development. Assessment and Evaluation in Higher Education, 33(6), 581-598. https://doi.org/10.1080/02602930701772804

Aragon, R., \& Wickramasinghe, I. P. (2016). What has an impact on grades? Instructor-made videos, communication, and timing in an online statistics course. Journal of Humanistic Mathematics, 6(2), 84-95. https://doi.org/10.5642/jhummath.201602.07

Blunsdon, B., Reed, K., McNeil, N., \& McEachern, S. (2003). Experiential learning in social science theory: An investigation of the relationship between student enjoyment and learning. Higher Education Research and Development, 22(1), 43-56. https://doi.org/10.1080/0729436032000056544

Corbridge, S. J., Robinson, F. P., Tiffen, J., \& Corbridge, T. C. (2010). Online learning versus simulation for teaching principles of mechanical ventilation to nurse practitioner students. International Journal of Nursing Education Scholarship, 7(1). https://doi.org/10.2202/1548-923X.1976

Crawford, J., Butler-Henderson, K., Rudolph, J., Malkawi, B., Glowatz, M., Magni, P., \& Lam, S. (2020). COVID-19: 20 countries' higher education intra-period digital pedagogy responses. Journal of Applied Learning \& Teaching, 3(1). https://doi.org/10.37074/jalt.2020.3.1.7 
Creswell, J. W., Piano Clark, V. L., Gutmann, M. L., \& Hanson, W. E. (2003). An expanded typology for classifying mixed methods research into designs. SAGE Open Medicine, 159-196. https://us.corwin.com/sites/default/files/upm-binaries/19291_Chapter_7.pdf

Gee, J. P. (2007). Good video games + good learning: Collected essays on video games, learning, and literacy. Bern, Switzerland: Peter Lang US. https://doi.org/10.3726/978-1-4539-1162-4

Green, J. L., Camilli, G., \& Elmore, P. B. (2012). Handbook of complementary methods in education research. Routledge. https://books.google.co.uk/books?id=91-OAgAAQBAJ

Hajhashemi, K., Caltabiano, N., \& Anderson, N. (2017). Net-geners' perceptions of engagement through online videos. Journal of Computers in Education, 4(3), 321-337. https://doi.org/10.1007/s40692-017-0084-7

Kessler, G., \& Plakans, L. (2001). Incorporating ESOL learners' feedback and usability testing in instructor-developed CALL materials. TESOL Journal, 10(1), 15-20. https://www.learntechlib.org/p/91087

King, S., Greidanus, E., Carbonaro, M., Drummond, J., Boechler, P., \& Kahlke, R. (2010). Synchronous problem-based e-learning (ePBL) in interprofessional health science education. Journal of Interactive Online Learning, 9(2), 133-150. https://doi.org/10.7939/R39872

McAlister, R. B. (2014). Use of instructor-produced YouTube ${ }^{\circledR}$ videos to supplement manual skills training in occupational therapy education. American Journal of Occupational Therapy, 68(Supplement 2), S67-S72. https://doi.org/10.5014/ajot.2014.685S04

Mechling, L. C., Ayres, K. M., Foster, A. L., \& Bryant, K. J. (2013). Comparing the effects of commercially available and custom-made video prompting for teaching cooking skills to high school students with autism. Remedial and Special Education, 34(6), 371-383. https://doi.org/10.1177/0741932513494856

Murphy, R. J., Gray, S. A., Straja, S. R., \& Bogert, M. C. (2004). Student learning preferences and teaching implications. Journal of Dental Education, 659-866. https://doi.org/10.1002/j.0022-0337.2004.68.8.tb03835.x

Palechka, G., \& MacDonald, R. (2010). A comparison of the acquisition of play skills using instructor-created video models and commercially available videos. Education and Treatment of Children, 33(3), 457-474. https://doi.org/10.1353/etc. 0.0100

Pan, G., Sen, S., Starrett, D. A., Bonk, C. J., Rodgers, M. L., Tikoo, M., \& Powell, D. V. (2012). Instructor-made videos as a learner scaffolding tool. MERLOT Journal of Online Learning and Teaching, 8(4), 298-311. http://publicationshare.com/Instructor_Videos_Pan_Bonk_et_al_JOLT_MERLOT.pdf

Ranga, J. S. (2017). Customized videos on a YouTube channel: A beyond the classroom teaching and learning platform for general chemistry courses. Journal of Chemical Education, 94, 10. https://doi.org/10.1021/acs.jchemed.6b00774

Reinert, H. (1976). One picture is worth a thousand words? Not necessarily! The Modern Language Journal, 60(4), 160-168. https://doi.org/10.2307/326308

Rose, K. K. (2009). Student perceptions of the use of instructor-made videos in online and face-to-face classes. MERLOT Journal of Online Learning and Teaching, 5(3), 487-495. http://jolt.merlot.org/vol5no3/rose_0909.pdf

Sandelowski, M. (2000). Focus on research methods: Combining qualitative and quantitative sampling, data collection, and analysis techniques in mixed-method studies. Research in Nursing and Health, 23(3), 246-255. https://doi.org/10.1002/1098-240X(200006)23:3<246::AID-NUR9>3.0.CO;2-H

Schönwetter, D., Gareau-Wilson, N., Cunha, R., \& Mello, I. (2016). Assessing the impact of voice-over screen-captured presentations delivered online on dental students' learning. Journal of Dental Education, 80, 141-148. https://doi.org/10.1002/j.0022-0337.2016.80.2.tb06069.x

Shackelford, J. L., \& Maxwell, M. (2012). Contribution of Learner-Instructor Interaction to Sense of Community in Graduate Online Education, 8(4), 248-260. https://jolt.merlot.org/vol8no4/shackelford_1212.pdf

Subramanian, A., Timberlake, M., Mittakanti, H., Lara, M., \& Brandt, M. L. (2012). Novel educational approach for medical students: Improved retention rates using interactive medical software compared with traditional lecture-based format. Journal of Surgical Education, 69(4), 449-452. https://doi.org/10.1016/j.jsurg.2012.05.013

Tymczyńska, M. (2009). Integrating in-class and online learning activities in a healthcare interpreting course using Moodle. The Journal of Specialised Translation, 12, 148-164. 


\section{Appendix A}

IMV topics:

1. PTA Top Tips

2. Rules for Masking

3. Rules of Masking Song

4. Degrees of Hearing Loss

5. Types of Hearing Loss

\section{Copyrights}

Copyright for this article is retained by the author(s), with first publication rights granted to the journal.

This is an open-access article distributed under the terms and conditions of the Creative Commons Attribution license (http://creativecommons.org/licenses/by/4.0/). 